\title{
Genome-Wide Association Mapping of Fusarium Head Blight Resistance in Spring Wheat Lines Developed in the Pacific Northwest and CIMMYT
}

\author{
Rui Wang, Jianli Chen, † James A. Anderson, Junli Zhang, Weidong Zhao, Justin Wheeler, Natalie Klassen, \\ Deven R. See, and Yanhong Dong
}

First, second, fifth, sixth, and seventh authors: Department of Plant, Soil, and Entomological Sciences, University of Idaho, Aberdeen; third author: Department of Agronomy and Plant Genetics, University of Minnesota, St. Paul; fourth author: Department of Plant Sciences, University of California-Davis, Davis; eighth author: United States Department of Agriculture-Agricultural Research Service, Wheat Genetics, Quality, Physiology and Disease Research Unit, Pullman, WA 99164; and ninth author: Department of Plant Pathology, University of Minnesota, St. Paul.

Accepted for publication 11 July 2017.

\begin{abstract}
Fusarium head blight (FHB) is a destructive disease of wheat in humid and semihumid areas of the world. It has emerged in the Pacific Northwest (PNW) in recent years because of changing climate and crop rotation practices. Our objectives in the present study were to identify and characterize quantitative trait loci (QTL) associated with FHB resistance in spring wheat lines developed in the PNW and the International Maize and Wheat Improvement Center. In total, 170 spring wheat lines were evaluated in field and greenhouse trials in 2015 and 2016. Fourteen lines showing consistent resistance in multiple environments were identified. These lines are valuable resources in wheat variety improvement of FHB resistance

because they have no Sumai 3 or Sumai 3-related background. The 170 lines were genotyped using a high-density Illumina $90 \mathrm{~K}$ single-nucleotide polymorphisms (SNP) assay and 10 other non-SNP markers. A genomewide association analysis was conducted with a mixed model $(\mathrm{Q}+\mathrm{K})$. Consistent, significant SNP associations with multiple traits were found on chromosomes 1B, 2B, 4B, 5A, 5B, and 6A. The locus on chromosome $5 \mathrm{~B}$ for reduced deoxynivalenol content may be novel. The identified QTL are being validated in additional mapping studies and the identified resistant lines are being used in variety development for FHB resistance and facilitated by marker-assisted selection.
\end{abstract}

Fusarium head blight (FHB), caused by Fusarium graminearum Schwabe (teleomorph: Gibberella zeae) and F. culmorum (Wm. G. Sm.) Sacc. (teleomorph: unknown), is one of the most important fungal diseases of wheat and other cereals in the United States and many other regions of the world (Windels 2000). In addition to causing severe yield losses, the two FHB pathogens are known to produce two important mycotoxins, deoxynivalenol (DON) and zearalenone, resulting in inferior quality grain due to mycotoxin contamination (Bai et al. 2001; Desjardins et al. 1993). Although the disease is more severe in humid and semihumid areas of the world, it is becoming a problem for growers in Idaho and some other areas in the Pacific Northwest (PNW), due to increased corn production, reduced tillage, and changing climate (Marshall et al. 2012). Currently, most cultivars grown in Idaho and the PNW region are susceptible to FHB and often accumulate high levels of DON toxin (Marshall 2014). Only two cultivars grown in the region, hard red 'Volt' and soft white 'UI Stone', are considered to be less susceptible (Marshall 2014).

Use of host resistance is a key component in reducing the impacts of FHB on cereal yield and mycotoxin contamination (Bai and Shaner 1996). Host resistance to FHB has been classified into five types, as follows: type I (resistance to initial infection), type II (resistance to disease spread on spikes), type III (resistance to toxin content), type IV (resistance to kernel infection), and type V (tolerance to disease) (Mesterhazy 1995; Mesterhazy et al. 1999; Schroeder and Christensen 1963). Type II is the primary type of resistance that has been used in the past six decades. Several

†Corresponding author: J. Chen; E-mail: jchen@uidaho.edu

*The $\boldsymbol{e}$-Xtra logo stands for "electronic extra" and indicates that three supplementary figures and five supplementary tables are published online.

(c) 2017 The American Phytopathological Society breeding lines and cultivars have been developed in the United States using the Fhbl resistance derived from the Chinese line 'Sumai 3' (plant introduction [PI] 481542), including the lines VA04W-433 and VA04W-474 from Virginia Tech (Chen et al. 2007) and 'Alsen' at North Dakota State University (Mergoum et al. 2007). To develop durable FHB resistance and enhance genetic diversity, a substantial breeding effort had been invested to identify and facilitate pyramiding of novel resistance genes other than Fhbl. For example, a quantitative trait locus (QTL) on 5AS had been widely used in marker-assisted selection (MAS) and genomic selection of FHB resistance in the Great Plains and Atlantic coast wheat-growing regions in the United States (Chen et al. 2007). Recently, Arruda et al. (2016) evaluated a panel consisting of 273 U.S. winter wheat breeding lines and identified a few FHB resistance QTL using genome-wide association mapping.

However, the FHB resistance in PNW-developed germplasm and cultivars has not been well characterized (Chen and Marshall 2012). There is no published research describing QTL associated with FHB resistance in PNW-developed wheat lines. The objectives of the present study were to characterize FHB resistance in 170 spring wheat lines developed in the PNW and the International Maize and Wheat Improvement Center (CIMMYT) and to identify QTL conferring resistance using the genome-wide association analysis (GWAS) method and the high-density $90 \mathrm{~K}$ single-nucleotide polymorphism (SNP) markers.

\section{MATERIALS AND METHODS}

Plant materials. In total, 170 spring wheat cultivars and elite lines from the PNW and CIMMYT were evaluated for FHB disease reactions (Supplementary Table S1). The 170 lines (PNW panel hereafter) include 26 lines from the Washington State University (WSU), 33 from the University of Idaho (UI), 34 from the University 
of California, Davis (UCD), 25 from Montana State University (MSU), 49 from CIMMYT, 1 from Agriculture and Agri-Food Canada, Saskatchewan (SSK), and 2 from Limagrain Cereal Seeds (LCS). Of these, 143 had been assessed previously for the root morphology (Narayanan and Prasad 2014) and rust resistance (Bajgain et al. 2015) as part of the Triticeae Coordinated Agricultural Project (TCAP, https://www.triticeaecap.org/).

Disease assessment. All lines were grown as 1-m headrows in three locations in 2015 (St. Paul, MN [StP], Crookston, MN [CrK], and Aberdeen, ID [AB]) and two locations in 2016 (StP and AB). One or two replications were planted in different field trials over 2 years. The panel was also screened in a greenhouse $(\mathrm{GH})$ in 2015 and 2016, with four replications of each line. Checks were replicated throughout the field and greenhouse tests to provide estimates of differences among plots and to determine the resistance level of the tested lines. Alsen, 'BacUp', 'W14', and 'AC BARRIE' were used as resistant or moderately resistant checks (Chen et al. 2006; Zhang et al. 2016), while 'Roblin', 'Wheaton', and 'UI Platinum' were used as susceptible or moderately susceptible checks (Chen and Marshall 2012; Zhang et al. 2016) in the field and greenhouse experiments.

The inoculum preparation and inoculation in the StP and CrK nurseries were described in detail by Zhang et al. (2016). Briefly, the plots in the StP nursery were individually sprayed with an $F$. graminearum conidial suspension at $1 \times 10^{4} \mathrm{spores} / \mathrm{ml}$ using a $\mathrm{CO}_{2}$-pressure backpack sprayer. Plots were inoculated at anthesis and inoculated again 3 to 4 days later. The plots in the CrK nursery were inoculated with corn spawn. Colonized grain was spread at the jointing stage and 1 week later. Both nurseries were misted immediately after inoculation to promote infection. In the $A B$ nursery, the pathogen ( $F$. culmorum) was isolated from infected seed and the inoculum was harvested from the culture using tap water and diluted for inoculation. The plots in this nursery were spray inoculated three times based on heading and flowering dates (one time on heading and twice during flowering) with conidial suspension at $5 \times 10^{4}$ spores $/ \mathrm{ml}$. A fine overhead misting system was installed and a wheat border planted to help maintain moisture and reduce drying by wind. Plants in greenhouse experiments were point inoculated during anthesis. Two to three spikes in each plant were inoculated in the central spikelet of a spike with approximately $5 \mu \mathrm{l}$ of macroconidial suspension at the concentration of 8 to $10 \times$ $10^{4} / \mathrm{ml}$ using a pipette dropper. The inoculated plants were then put under automatic misting benches for $48 \mathrm{~h}$ to provide favorable humidity for infection.

FHB disease incidence, severity, FHB index [(incidence $\times$ severity)/ $100]$, and DON content were assessed. Incidence was recorded as the percentage of infected spikes in a plot. Severity was visually calculated as the percentage of infected spikelets in each spike. In Minnesota, the assessment was performed at 21 days after inoculation, whereas in $\mathrm{AB}$ and $\mathrm{GH}$ experiments, the assessments were performed 28 days after inoculation. DON content ( $\mathrm{ppm}$ ) was measured using grain samples from 30 randomly selected heads for each line in the StP and CrK nurseries and from the composite of all plants in the $\mathrm{AB}$ nursery. The procedure to quantify the DON content was described by Fuentes et al. (2005) and Mirocha et al. (1998). Briefly, $4 \mathrm{~g}$ of ground sample was extracted with $16 \mathrm{ml}$ of acetonitrile/water (84:16 [vol/vol]). The sample was shaken for $1 \mathrm{~h}$ and then $4 \mathrm{ml}$ of extract was passed through a column packed with $\mathrm{C} 18$ and aluminum oxide (1:3). The filtrate $(1 \mathrm{ml})$ was evaporated to dryness under nitrogen at room temperature and derivatized by silylating reagent for gas chromatography-mass spectrometry (GC/MS) analysis. A temperature program was used for GC/MS analysis and then selected ion monitoring was applied to detect the characteristic ions of DON with fragment ion ( $\mathrm{m} / \mathrm{z}$ value) of 235.10 as target ion and 259.10 and 422.10 as reference ions.

Phenotypic data analysis. Each year-location combination was considered as an environment in our study. Severity was assessed in seven environments (AB15, AB16, CrK15, StP15, StP16, GH15, and GH16), whereas incidence, FHB index, and the DON content were evaluated in four environments. For each environment, the arithmetic mean of phenotypic observations in all replications was used as the phenotypic data. The best linear unbiased predictions (BLUP) across different environments for each trait were estimated using R package "Ime4" (Bates et al. 2015; R Core Team 2016). The genotypes, environments, and replications were all considered random effects in the model. For each trait, all of the single-environment phenotypic data sets and BLUP data were used for further analysis. Broad sense heritability $\left(H^{2}\right)$ was estimated according to the equation $H^{2}=\sigma_{G}^{2} /\left(\sigma_{G}^{2}+\sigma_{G E}^{2} / r+\sigma_{e}^{2} / r e\right)$, where $\sigma_{G}^{2}$ is the variance of genotypes, $\sigma_{G E}^{2}$ is the variance of genotypeenvironment interaction, $\sigma_{e}^{2}$ is the residual variance, and $e$ and $r$ represent the number of environment and the number of replications, respectively, in each environment.

The phenotyping distributions were analyzed and illustrated using histogram plots in the JMP Genomics statistical suite (v8.0; SAS Institute, Cary, NC). Furthermore, correlation coefficients among different environments and among different traits were calculated in JMP Genomics v8.0 using the default statistic method.

Genotypic data analysis. The Illumina $90 \mathrm{~K}$ genotyping data for 143 lines from the subset of SWAM Panel were downloaded from the Triticeae Toolbox (T3) website (https://triticeaetoolbox. org/wheat/) developed by T-CAP. The remaining 27 lines were genotyped with the high-density Illumina 90K SNP assay at the United States Department of Agriculture-Agricultural Research Service (USDA-ARS) Cereal Crops Research Unit, Fargo, ND and the allele calls were performed using GenomeStudio (v2011.1; Illumina Inc., Hayward, CA). After combining these two sets of genotyping data, 11,523 common SNP markers were selected. Then, 10 other non-SNP markers, including the STS marker umn10 for the Fhbl locus, were incorporated to the genotyping data. After exclusion of SNP markers either with missing calls more than $10 \%$ accessions or with minor allele frequency less than $0.05,10,178$ markers were finally used in association analysis. Genetic positions for the selected SNP markers were based on the consensus map for 90K SNP markers developed by Wang et al. (2014) and were downloaded from the T3 website. The marker coverage, polymorphic information content (PIC) value, and gene diversity for each SNP were calculated in the whole genome and each A, B, and D genome using JMP Genomics v8.0.

Linkage disequilibrium and population structure analysis. JMP Genomics v8.0 was used to calculate the linkage disequilibrium (LD) squared correlation coefficient $\left(r^{2}\right)$ for the whole genome in the whole panel and five subclusters, and subsequently for each $\mathrm{A}, \mathrm{B}$, and $\mathrm{D}$ genome in the whole panel. By plotting pairwise $r^{2}$ values against the distance in centimorgans (cM) between adjacent SNP loci, the LD decay in terms of genetic distance was estimated at the intersection point of the smoothing spline-fitting curve and the critical threshold line. The method to calculate the critical $r^{2}$ threshold was described by Wang et al. (2017) and all LD values beyond this critical $r^{2}$ value were considered to be caused by genetic linkage.

The familial relatedness among the PNW panel was calculated using the method of Identity by State (IBS) in JMP Genomics v8.0. Cluster analysis was conducted in JMP Genomics v8.0 using hierarchical clustering with the Fast Ward method. To correct population structure in association analysis, principal component analysis (PCA) was conducted in JMP Genomics v8.0 and was illustrated with a three-dimensional scatterplot. The principal components (PC) explaining approximately $25 \%$ of cumulative variation were chosen and used in the association analysis (Tamang et al. 2015; Wang et al. 2017).

GWAS. Association analyses were performed with four different models, including (i) naïve $=$ general linear model with no correction for population structure, (ii) PCA = general linear model with corrected population structure using the first six PC (Q), (iii) IBS = mixed linear model with the 170-by-170 relationship matrix (K), and (iv) IBS+PCA = mixed linear model with the combination of $\mathrm{K}$ and $\mathrm{Q}$ to correct the analysis. The Sawa Bayesian information 
criterion (BIC) was calculated in JMP Genomics v8.0 and used to fit the best models for each trait and each data set. For the best models, a positive false discovery rate ( $p$ FDR; $q$ value) was calculated (Storey 2002) using JMP Genomics v8.0.

To assign colocated or adjacent significant markers into a unique QTL, the criterion of genetic distance less than $8.66 \mathrm{cM}$ (the LD decay for whole genome) was used. Most QTL identified followed this criterion, with only one exception: the locus Qfhb-1B had two flanking markers that were $13 \mathrm{cM}$ apart yet were in high LD at 0.71 and, thus, were assigned to a single QTL.

To classify marker-wise significance, two criteria with increasing stringency were used for two levels of significance (low and high). For low significant QTL nomination, the QTL was associated with a marker at $P$ value $<0.001$ and was detected in multiple datasets (at least two of five datasets for trait incidence, DON content, and FHB index and at least four of eight datasets for trait severity) using $P$ value cutoff of 0.01 . If the identified QTL using these criteria was associated with at least one marker at $q(p \mathrm{FDR})<0.1$, this QTL was considered to be a highly significant QTL.

\section{RESULTS}

Phenotypic data analysis. The phenotype distributions for incidence, severity, FHB index, and DON content were illustrated using histograms based on all single-environment datasets and BLUP values (Fig. 1). Although the disease levels showed some differences for different environments, most correlations for incidence, severity, FHB index, and DON content were significantly correlated among different environments (Table 1). The broadsense heritability for the four traits ranged from 0.37 to 0.56 , indicating that the panel contains adequate levels of genetic variation for the traits. In addition, based on BLUP values, different trait assessments were positively correlated, indicating the close genetic relationship between different types of resistance (Table 1).

Based on four types of disease assessments, 14 lines showing consistent resistance were identified in this study. The average of disease mean reactions across multiple environments of the 14 lines was much smaller than the average of the whole panel (Table 2). In all, 4 of them (PI 610750 from UCD, VIDA from MSU, and 9232 and 9248 from CIMMYT) showed resistance levels comparable with the resistant check Alsen and W14, which contains Fhb1 QTL, and the other 10 showed resistance levels comparable with the moderately resistant check AC BARRIE (Table 2).

Genotypic data analysis. Among the 10,178 markers, position assignments were available for 8,673 and these were distributed over all 21 chromosomes. The B genome showed the highest number of SNP $(4,410)$, followed by the A genome $(3,319)$ and D genome (944). The number of SNP markers varied among chromosomes, with a minimum of 34 markers on chromosome 4D and a maximum of 831 on $2 \mathrm{~B}$ (Table 3 ). As expected, the marker coverage for the $\mathrm{A}$ and $\mathrm{B}$ genomes (1.87 to 5.04 markers/cM) greatly exceeded that of the D genome ( 0.20 to 2.23 markers/cM) (Table 3$)$. PIC values for all SNP ranged from 0.11 to 0.38 , with an average of 0.31 . In total, $84 \%$ of the markers displayed PIC values exceeding 0.25 , demonstrating the informativeness of these markers. The average PIC value and gene diversity for genomes $\mathrm{A}, \mathrm{B}$, and D were similar at 0.28 to 0.29 and 0.35 to 0.36 , respectively.

LD and population structure analysis. The critical $r^{2}$ threshold values for the whole genome and genomes A, B, and D in the whole panel were similar to each other and were estimated at $0.07,0.07,0.06$, and 0.08 , respectively. By plotting the pairwise square of correlation coefficient $\left(r^{2}\right)$ values against the genetic distance, the LD decay values in terms of genetic distances were $8.66,8.95,9.30$, and $13.73 \mathrm{cM}$ for the whole genome and genome A, B, and D, respectively (Supplementary Fig. S1). The LD decay values estimated for the whole panel in this study are similar to those reported previously (Bajgain et al. 2015; Chao et al. 2010; Kollers et al. 2013). In addition, the LD decays for the whole panel and each subcluster were compared. Based on the critical $r^{2}$ threshold values at 0.1 , the LD of whole panel decayed the fastest at $5.5 \mathrm{cM}$, whereas the LD decays of cluster 3, 4, and 5 were at 7.5 to $12.9 \mathrm{cM}$. The LD of cluster 1 and 2 decayed the slowest at 22.5 and $36.0 \mathrm{cM}$ (Supplementary Fig. S2).

Based on the IBS matrix, the PNW panel were grouped into five clusters using the hierarchical clustering method. This population structure showed a tight association with the breeding program origin of the lines in the PNW panel (Supplementary Fig. S3). Clusters 1 to 5 ( $\mathrm{C} 1$ to $\mathrm{C} 5$ ) were mainly represented by lines from breeding programs at MSU, UI, UCD, CIMMYT, and WSU, respectively. In each cluster, there were a few lines from other
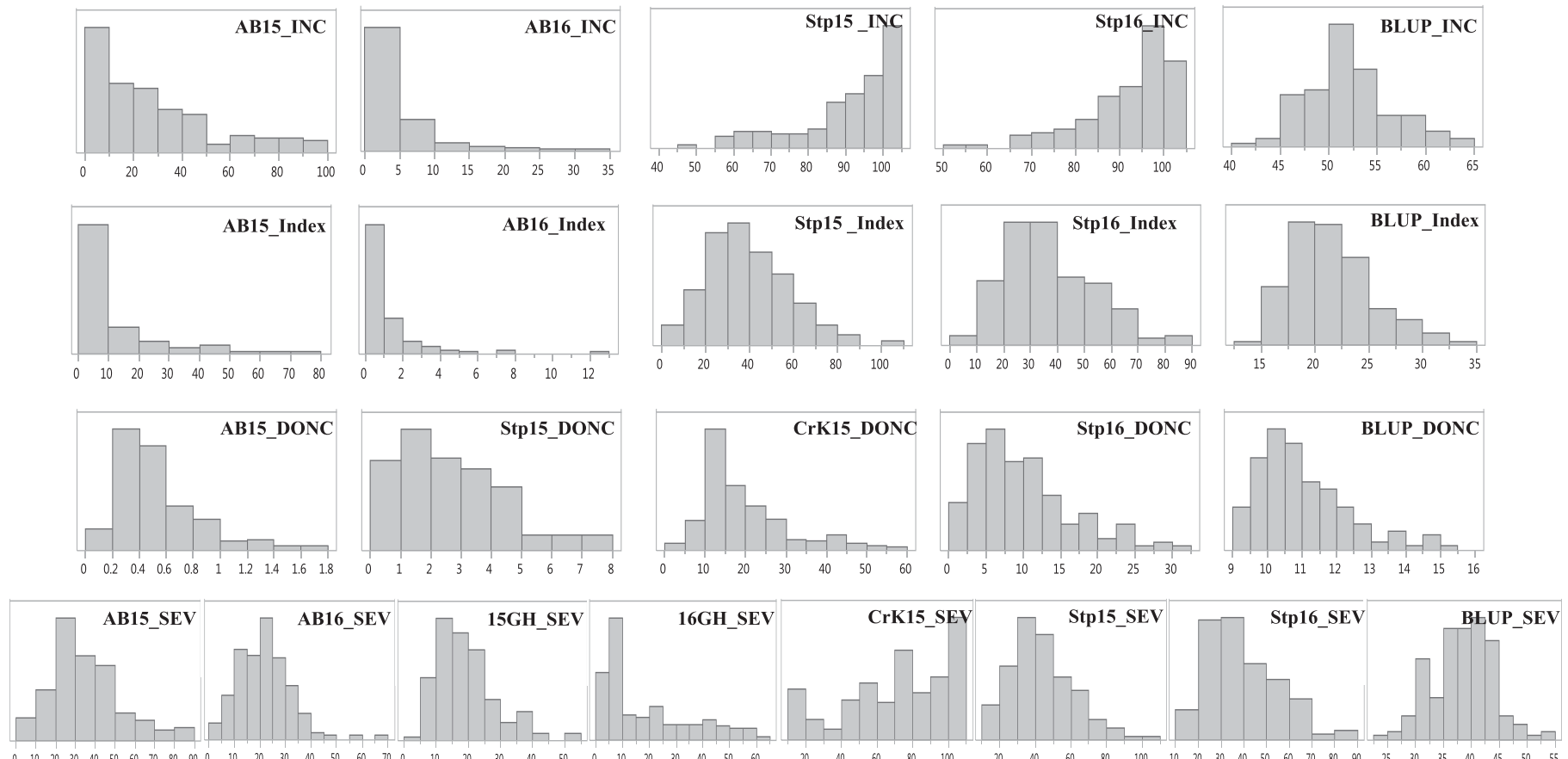

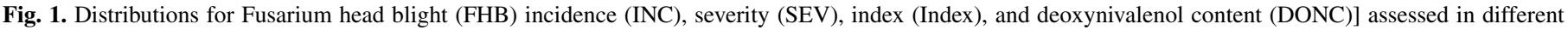
environments in the Pacific Northwest spring wheat panel. 
breeding programs, reflecting the sharing of the breeding lines. The population stratification among the lines was also analyzed by PCA. The first to third PC values explained 6.4, 6.0, and $4.9 \%$ genetic variation of the panel, respectively. Five clusters corresponding to the hierarchical clustering method were also identified in PCA. Cluster 5 (wheat lines from WSU program) was more distant from other clusters, which is also shown in hierarchical clustering results.

Marker associations to different traits. Four statistical models were evaluated in their fitness to conduct the association analysis and the BIC was used as the model fitness criterion. As reported in other studies in wheat and barley (Arruda et al. 2016; Wang et al. 2017), the mixed linear models that included the K matrix performed similarly to each other and provided better corrections for association analysis than models without K (Supplementary Table S2). In this study, the Q+K mixed linear model showed the smallest BIC values for all four traits across all environments and were selected for all GWAS analyses.

Incidence. A QTL on chromosome 2B (Qfhb-2B-1) was detected for the resistance to incidence at a high significance level and was

TABLE 1. Phenotypic data correlations ${ }^{\mathrm{a}}$

\begin{tabular}{|c|c|c|c|c|c|c|c|c|c|c|}
\hline \multirow[b]{2}{*}{ Location, year } & \multicolumn{7}{|c|}{ Location, year ${ }^{\mathrm{b}}$} & \multicolumn{3}{|c|}{ BLUPc $^{c}$} \\
\hline & StP15 & StP16 & CrK15 & $\mathrm{AB} 15$ & $\mathrm{AB} 16$ & $15 \mathrm{GH}$ & $16 \mathrm{GH}$ & INC & SEV & DONC \\
\hline \multicolumn{11}{|l|}{ Incidence } \\
\hline StP16 & $0.30 * * *$ & $\ldots$ & $\ldots$ & $\ldots$ & $\ldots$ & $\ldots$ & $\ldots$ & $\ldots$ & $\ldots$ & $\ldots$ \\
\hline $\mathrm{AB} 15$ & $0.33 * * *$ & $0.34 * * *$ & $\ldots$ & $\ldots$ & $\ldots$ & $\ldots$ & $\ldots$ & $\ldots$ & $\ldots$ & $\ldots$ \\
\hline AB16 & $0.28 * * *$ & $0.24 * *$ & $\ldots$ & $0.50 * * *$ & $\ldots$ & $\ldots$ & $\ldots$ & $\ldots$ & $\ldots$ & $\ldots$ \\
\hline BLUP & $0.66 * * *$ & $0.60 * * *$ & $\ldots$ & $0.88 * * *$ & $0.60 * * *$ & $\ldots$ & $\ldots$ & $\ldots$ & $\ldots$ & $\ldots$ \\
\hline \multicolumn{11}{|l|}{ Severity } \\
\hline Stp16 & $0.35 * * *$ & $\ldots$ & $\ldots$ & $\cdots$ & $\cdots$ & $\cdots$ & $\cdots$ & $\ldots$ & $\cdots$ & $\cdots$ \\
\hline CrK15 & $0.39 * * *$ & $0.31 * * *$ & $\ldots$ & $\ldots$ & $\ldots$ & $\ldots$ & $\ldots$ & $\ldots$ & $\ldots$ & $\ldots$ \\
\hline $\mathrm{AB} 15$ & $0.09 \mathrm{~ns}$ & $0.18^{*}$ & $0.17 *$ & $\ldots$ & $\ldots$ & $\ldots$ & $\ldots$ & $\ldots$ & $\ldots$ & $\ldots$ \\
\hline AB16 & $0.17 *$ & $0.21 * *$ & $0.18 *$ & $0.07 \mathrm{~ns}$ & $\ldots$ & $\ldots$ & $\ldots$ & $\ldots$ & $\ldots$ & $\ldots$ \\
\hline $15 \mathrm{GH}$ & $0.16^{*}$ & $0.33 * * *$ & $0.18 *$ & $0.02 \mathrm{~ns}$ & $0.11 \mathrm{~ns}$ & $\ldots$ & $\ldots$ & $\ldots$ & $\ldots$ & $\ldots$ \\
\hline $16 \mathrm{GH}$ & $0.22 * *$ & $0.34 * * *$ & $0.21 * *$ & $0.09 \mathrm{~ns}$ & $0.07 \mathrm{~ns}$ & $0.52 * * *$ & $\ldots$ & $\ldots$ & $\ldots$ & $\ldots$ \\
\hline BLUP & $0.62 * * *$ & $0.65 * * *$ & $0.77 * * *$ & $0.41 * * *$ & $0.34 * * *$ & $0.47 * * *$ & $0.56^{* * *}$ & $\ldots$ & $\ldots$ & $\ldots$ \\
\hline \multicolumn{11}{|l|}{ FHB index } \\
\hline StP16 & $0.33 * * *$ & $\ldots$ & $\ldots$ & $\ldots$ & $\cdots$ & $\ldots$ & $\ldots$ & $\ldots$ & $\ldots$ & $\ldots$ \\
\hline $\mathrm{AB} 15$ & $0.26 * * *$ & $0.27 * * *$ & $\ldots$ & $\ldots$ & $\ldots$ & $\ldots$ & $\ldots$ & $\ldots$ & $\ldots$ & $\ldots$ \\
\hline AB 16 & $0.30 * * *$ & $0.20 *$ & $\ldots$ & $0.37 * * *$ & $\ldots$ & $\ldots$ & $\ldots$ & $\ldots$ & $\ldots$ & $\ldots$ \\
\hline BLUP & $0.78 * * *$ & $0.74 * * *$ & $\ldots$ & $0.64 * * *$ & $0.43 * * *$ & $\ldots$ & $\ldots$ & $\ldots$ & $\ldots$ & $\ldots$ \\
\hline \multicolumn{11}{|l|}{ DON content } \\
\hline StP16 & $0.14 \mathrm{~ns}$ & $\ldots$ & $\ldots$ & $\ldots$ & $\ldots$ & $\ldots$ & $\ldots$ & $\ldots$ & $\ldots$ & $\ldots$ \\
\hline CrK15 & $0.35 * * *$ & $0.28 * * *$ & $\ldots$ & $\ldots$ & $\ldots$ & $\ldots$ & $\ldots$ & $\ldots$ & $\ldots$ & $\ldots$ \\
\hline $\mathrm{AB} 15$ & $0.25 * *$ & $0.23 * *$ & $0.22 * *$ & $\ldots$ & $\ldots$ & $\ldots$ & $\ldots$ & $\ldots$ & $\ldots$ & $\ldots$ \\
\hline BLUP & $0.36 * * *$ & $0.65 * * *$ & $0.89 * * *$ & $0.18 *$ & $\ldots$ & $\ldots$ & $\ldots$ & $\ldots$ & $\ldots$ & $\ldots$ \\
\hline \multicolumn{11}{|l|}{ Between traits } \\
\hline BLUP_SEV & $\ldots$ & $\ldots$ & $\ldots$ & $\ldots$ & $\ldots$ & $\ldots$ & $\ldots$ & $0.48 * * *$ & $\ldots$ & $\ldots$ \\
\hline BLUP_DONC & $\ldots$ & $\ldots$ & $\ldots$ & $\ldots$ & $\ldots$ & $\ldots$ & $\ldots$ & $0.16^{*}$ & $0.48 * * *$ & $\ldots$ \\
\hline BLUP_Index & $\ldots$ & $\ldots$ & $\ldots$ & $\ldots$ & $\ldots$ & $\ldots$ & $\ldots$ & $0.77 * * *$ & $0.77 * * *$ & $0.34 * * *$ \\
\hline
\end{tabular}

a Fusarium head blight (FHB) incidence (INC), severity (SEV), deoxynivalenol content (DONC), and index (Index); ***, **, and * indicate $P<0.001,0.01$, and 0.05 ; respectively; ns indicates not significant.

b Locations: St. Paul, MN (StP), Crookston, MN (CrK), Aberdeen, ID (AB), and the greenhouse (GH) in 2015 and 2016.

${ }^{c}$ BLUP $=$ best linear unbiased predictions.

TABLE 2. Mean Fusarium head blight (FHB) reactions of 14 resistant spring wheat lines across multiple environments and their haplotypes for six resistance quantitative trait loci (QTL)

\begin{tabular}{|c|c|c|c|c|c|c|c|c|c|c|c|c|}
\hline \multirow[b]{2}{*}{ Lines $^{\mathrm{a}}$} & \multirow[b]{2}{*}{ Origin $^{b}$} & \multirow[b]{2}{*}{ Cluster } & \multicolumn{4}{|c|}{ Mean $^{\mathrm{c}}$} & \multicolumn{6}{|c|}{ QTL } \\
\hline & & & INC & SEV & Index & DON & FHB-2B-1 & FHB-2B-2 & FHB-2B-3 & FHB-4B & FHB-5B-1 & FHB-5B-2 \\
\hline OTIS & WSU & 3 & 36.6 & 16.3 & 8.3 & 4.1 & + & + & - & + & + & + \\
\hline IDO851 & UI & 2 & 49.0 & 21.6 & 13.5 & 6.4 & - & + & - & + & + & + \\
\hline IDO671 & UI & 2 & 40.6 & 20.4 & 12.2 & 4.8 & - & + & - & + & + & + \\
\hline WHITEBIRD & UI & 2 & 40.8 & 13.8 & 11.4 & 4.3 & + & + & - & + & + & - \\
\hline PI 610750 & UCD & 4 & 33.5 & 8.4 & 3.9 & 2.7 & + & - & + & + & + & - \\
\hline VIDA & MSU & 1 & 36.0 & 21.4 & 6.6 & 3.0 & - & + & - & + & + & + \\
\hline MT0415 & MSU & 1 & 39.1 & 24.0 & 10.8 & 4.1 & + & + & - & + & + & + \\
\hline 9232 & CIMMYT & 4 & 37.6 & 21.9 & 7.1 & 2.8 & - & + & - & + & + & + \\
\hline 9245 & CIMMYT & 4 & 44.5 & 19.0 & 9.2 & 3.6 & - & + & - & + & + & + \\
\hline 9241 & CIMMYT & 3 & 47.5 & 25.3 & 12.8 & 2.8 & - & - & + & + & + & + \\
\hline 9248 & CIMMYT & 4 & 29.3 & 14.6 & 7.2 & 3.4 & - & + & + & + & - & + \\
\hline Resistance & $\ldots$ & $\ldots$ & 40.6 & 19 & 9.8 & 4.1 & $\ldots$ & $\ldots$ & $\ldots$ & $\ldots$ & $\ldots$ & $\ldots$ \\
\hline
\end{tabular}

${ }^{a}$ Resistance $=$ average of the resistance lines, Panel $=$ average of the whole panel, Alsen $=$ resistant check, and AC BARRIE $=$ moderately resistant check .

b Washington State University (WSU), University of Idaho (UI), University of California, Davis (UCD), Montana State University (MSU), and International Maize and Wheat Improvement Center (CIMMYT).

${ }^{c}$ Fusarium head blight (FHB) incidence (INC), severity (SEV), deoxynivalenol (DON) content, and FHB index. 
detected in all five datasets, indicating its stability (Figs. 2 and 3; Table 4). The additive effect of this QTL is a $17.17 \%$ reduction of the incidence, as illustrated in Figure 4. The most significantly associated SNP marker (BS00009962_51) for this QTL explained $13.25 \%$ of the variability and showed a $q$ value of 0.02 , indicating high significance (Table 4). QTL located on 2B (Qfhb-2B-2) and 6A (Qfhb-6A) were also associated with incidence reduction at the low significance level. The two most significantly associated markers for these two QTL explained 8.96 and $7.70 \%$ of the variability, respectively (Supplementary Table S3).

Severity. All three identified severity resistance QTL (Qfhb-2B-2, Qfhb-4B, and Qfhb-5B-1) were at the low significance level. However, these QTL were also identified for resistance to other traits at the high

TABLE 3. Marker statistics of the whole genome and three subgenomes in spring wheat association mapping panel ${ }^{\mathrm{a}}$

\begin{tabular}{|c|c|c|c|c|c|}
\hline Chromosome & $\begin{array}{l}\text { Length } \\
(\mathrm{cM})\end{array}$ & Markers & $\begin{array}{l}\text { Marker } \\
\text { coverage }\end{array}$ & $\begin{array}{l}\text { Average } \\
\text { PIC }\end{array}$ & $\begin{array}{l}\text { Average gene } \\
\text { diversity }\end{array}$ \\
\hline \multicolumn{6}{|l|}{ Genome A } \\
\hline $1 \mathrm{~A}$ & 156.30 & 523 & 3.35 & 0.28 & 0.35 \\
\hline $2 \mathrm{~A}$ & 177.65 & 487 & 2.74 & 0.31 & 0.40 \\
\hline $3 \mathrm{~A}$ & 197.20 & 369 & 1.87 & 0.26 & 0.32 \\
\hline $4 \mathrm{~A}$ & 164.13 & 405 & 2.47 & 0.29 & 0.37 \\
\hline $5 \mathrm{~A}$ & 148.30 & 428 & 2.89 & 0.29 & 0.36 \\
\hline $6 \mathrm{~A}$ & 141.08 & 539 & 3.82 & 0.29 & 0.37 \\
\hline $7 \mathrm{~A}$ & 241.40 & 568 & 2.35 & 0.28 & 0.34 \\
\hline All & $1,226.06$ & 3319 & 2.71 & 0.29 & 0.36 \\
\hline \multicolumn{6}{|l|}{ Genome B } \\
\hline 1B & 173.62 & 733 & 4.22 & 0.23 & 0.28 \\
\hline $2 \mathrm{~B}$ & 185.67 & 831 & 4.48 & 0.31 & 0.39 \\
\hline $3 \mathrm{~B}$ & 144.74 & 584 & 4.03 & 0.29 & 0.36 \\
\hline $4 B$ & 114.88 & 314 & 2.73 & 0.27 & 0.33 \\
\hline $5 B$ & 217.65 & 848 & 3.90 & 0.30 & 0.38 \\
\hline $6 \mathrm{~B}$ & 122.92 & 620 & 5.04 & 0.28 & 0.35 \\
\hline $7 \mathrm{~B}$ & 178.86 & 480 & 2.68 & 0.27 & 0.33 \\
\hline All & $1,138.34$ & 4410 & 3.87 & 0.28 & 0.35 \\
\hline \multicolumn{6}{|l|}{ Genome D } \\
\hline $1 \mathrm{D}$ & 179.54 & 235 & 1.31 & 0.30 & 0.39 \\
\hline $2 \mathrm{D}$ & 144.50 & 322 & 2.23 & 0.29 & 0.36 \\
\hline $3 \mathrm{D}$ & 165.18 & 111 & 0.67 & 0.26 & 0.32 \\
\hline $4 \mathrm{D}$ & 170.43 & 34 & 0.20 & 0.26 & 0.32 \\
\hline $5 \mathrm{D}$ & 207.33 & 76 & 0.37 & 0.27 & 0.34 \\
\hline $6 \mathrm{D}$ & 160.50 & 81 & 0.50 & 0.28 & 0.35 \\
\hline 7D & 223.52 & 85 & 0.38 & 0.29 & 0.36 \\
\hline All & $1,251.00$ & 944 & 0.75 & 0.28 & 0.35 \\
\hline $\begin{array}{l}\text { Whole } \\
\text { genome }\end{array}$ & $3,615.40$ & 8673 & 2.40 & 0.28 & 0.35 \\
\hline
\end{tabular}

a Marker coverage indicates the number of markers per centimorgan (cM) in the genetic map and PIC = polymorphic information content. significance level, indicating their multiple effects on reducing FHB. The most significant markers for these three QTL explained 8.06, 9.52 , and $7.82 \%$ of the variability, respectively.

FHB index. A QTL on chromosome 5B (Qfhb-5B-1) was detected for FHB index resistance at the high level of significance and was detected in four of five datasets (Figs. 2 and 3; Table 4), indicating its stability. The additive effect of this QTL is a $13.74 \%$ reduction of the FHB index (Fig. 4). Five colocated SNP markers at $20.23 \mathrm{cM}$ are significantly associated with this QTL, with an $q$ value at 0.07 , explaining 10.20 to $10.65 \%$ of the variability (Table 4 ). Another four QTL, located on 1B (Qfhb-1B), 2B (Qfhb-2B-1 and Qfhb-2B-2), and 5A (Qfhb-5A), were also associated with FHB index reduction at low significance levels.

DON content. For DON content, four QTL (Qfhb-2B-2, Qfhb-2B-3, Qfhb-4B, and Qfhb-5B-2) were identified at the high significance level in at least three of five datasets (Figs. 2 and 3; Table 4). The four QTL reduced DON content 26.89 to $32.69 \%$ (Fig. 4). The most significantly associated SNP markers with the four QTL explained 7.84 to $12.54 \%$ of the variability, and showed $q$ values from 0.01 to 0.05 , respectively (Table 4).

In summary, six QTL were identified at high significance levels and three QTL were identified at low significance levels. Four of six highly significant QTL were identified for resistance to more than one trait: Qfhb-2B-1 was identified for resistance to both FHB index and incidence, Qfhb-2B-2 was identified for resistance to all four traits, Qfhb-5B-1 was identified for resistance to both FHB index and severity, and Qfhb-4B was identified for resistance to both severity and DON content.

Additive effects of favorable alleles. It is well known that a relatively high number of quantitative loci control FHB resistance. To investigate and utilize more resistance loci involved in the present study, we fitted linear regression between the phenotyping data (FHB index_BLUP and DON content_BLUP) and the favorable allele numbers for all detected markers with $P$ value $<0.01$ in the BLUP datasets. There were 89 individual SNP markers significantly associated with FHB index (Supplementary Table S4). The total number of favorable alleles for each line ranged from 23 to 73 . The top 10 resistant lines with a mean favorable allele number of 63 showed an FHB index of 15.73, whereas the top 10 susceptible lines with a mean favorable allele number of 30 showed a significantly higher FHB index of 30.41. Correlation analysis showed a significantly negative relationship between the number of favorable alleles and FHB index_BLUP $(r=-0.62)$. Linear regression showed a linear dependence of FHB index and number of favorable alleles with $R^{2}=0.39$ and $y=30.75-0.18 x$ (Fig. 5A). These results indicated additive effects on FHB index reduction for the 89 SNP alleles.
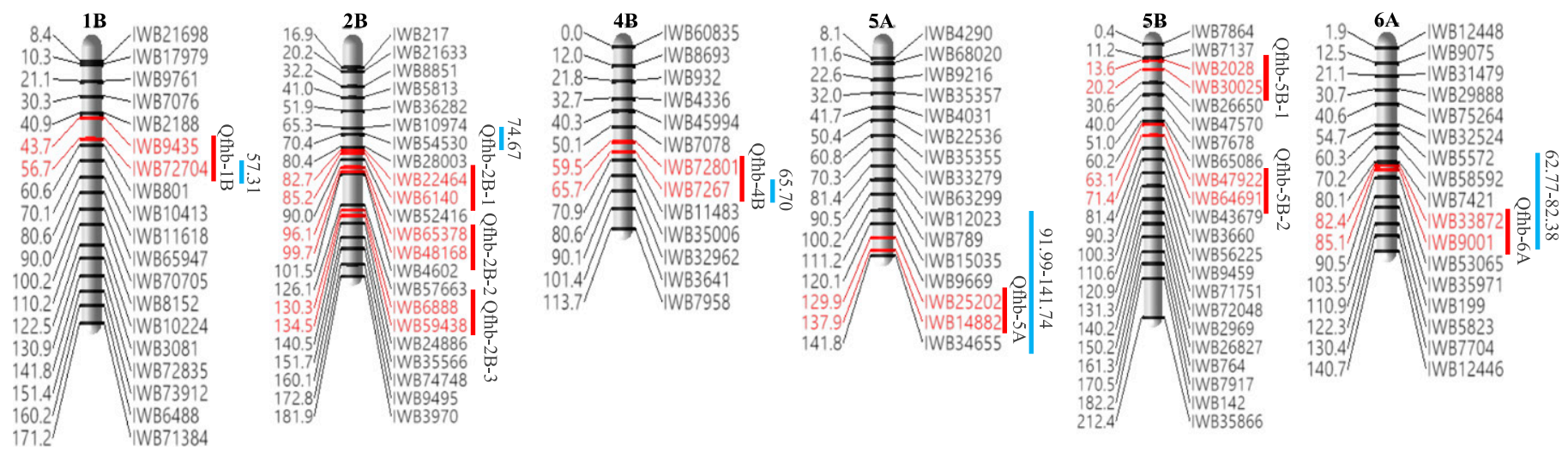

Fig. 2. Schematic chromosome locations of Fusarium head blight (FHB)-associated quantitative trait loci (QTL) identified in the Pacific Northwest spring wheat panel and comparison with QTL previously identified in a genome-wide association analysis study using 90K single-nucleotide polymorphism (SNP) markers by Jiang et al. (2015). Marker order and locations are based on the wheat consensus map for 90K SNP markers developed by Wang et al. (2014). Map distance in centimorgans is given on the left side and markers are shown on the right side of the chromosome. Some markers have been removed for display purpose. The QTL are indicated with dark bars on the right side of chromosomes. Two flanking SNP markers for each QTL are marked by medium shading. Previously mapped FHB resistance QTL in Jiang et al. (2015) are indicated on the right side of chromosomes with light bars. 
Similarly, for DON content regression, there were 89 individual SNP markers significantly associated with DON content (Supplementary Table S5). The number of favorable alleles for each line ranged from 11 to 79. The top 10 resistant lines with a mean favorable allele number of 62 showed a DON content of 9.28, whereas the top 10 susceptible lines with a mean favorable allele number of 30 showed significantly higher DON content of 14.34. Correlation analysis showed a significantly negative relationship between the number of favorable alleles and the DON content $(r=-0.67)$. Linear regression showed a linear dependence of DON content and number of favorable alleles with $R^{2}=0.45$ and $y=14.37-0.06 x$ (Fig. 5B). These results indicated additive effects on DON content for the 89 SNP alleles.

\section{DISCUSSION}

Historically, FHB disease has been infrequent and generally not damaging in Idaho and the other PNW states. However, the FHB occurrence and severity on spring wheat and barley in the last few years has increased to the point that it is considered a threat to the wheat and malting barley crops. This study first assessed FHB resistance for a PNW spring wheat panel in seven trials in two states over 2 years. Fourteen of the tested lines were identified with consistent resistance to FHB as assessed using four measurements of disease (incidence, severity, FHB index, and DON content). These resistant lines are grouped into four clusters and come from five breeding programs: one from the WSU program, three from the UI program, three from the UCD program, two from the MSU program, and four from the CIMMYT program. This result indicates the genetic diversity of the resistance resources in this panel. These resistant lines have no Sumai 3 or Sumai 3-related background, providing valuable resources in wheat variety improvement of FHB resistance. The haplotypes of the 14 lines for the six highly significant QTL are shown in Table 2. The resistance QTL and associated SNP markers will be used for MAS, either as direct selection markers or as flanking markers to develop more user-friendly and closely
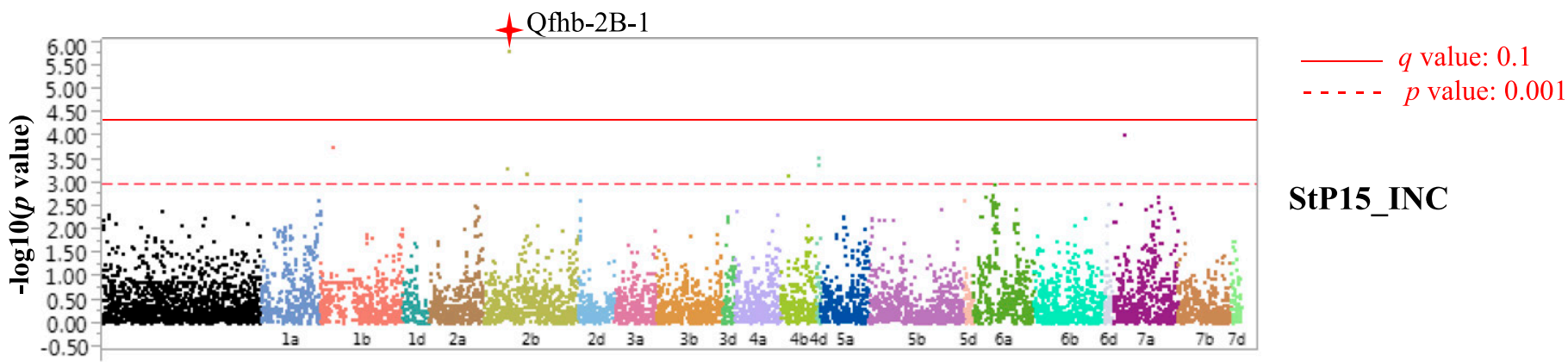

\section{StP15_INC}

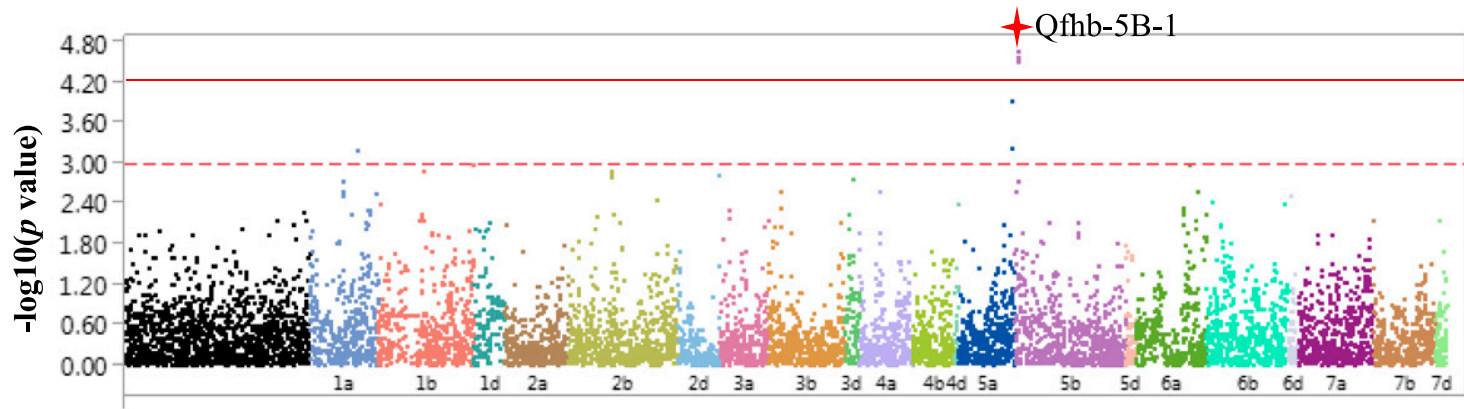

\section{BLUP_Index}

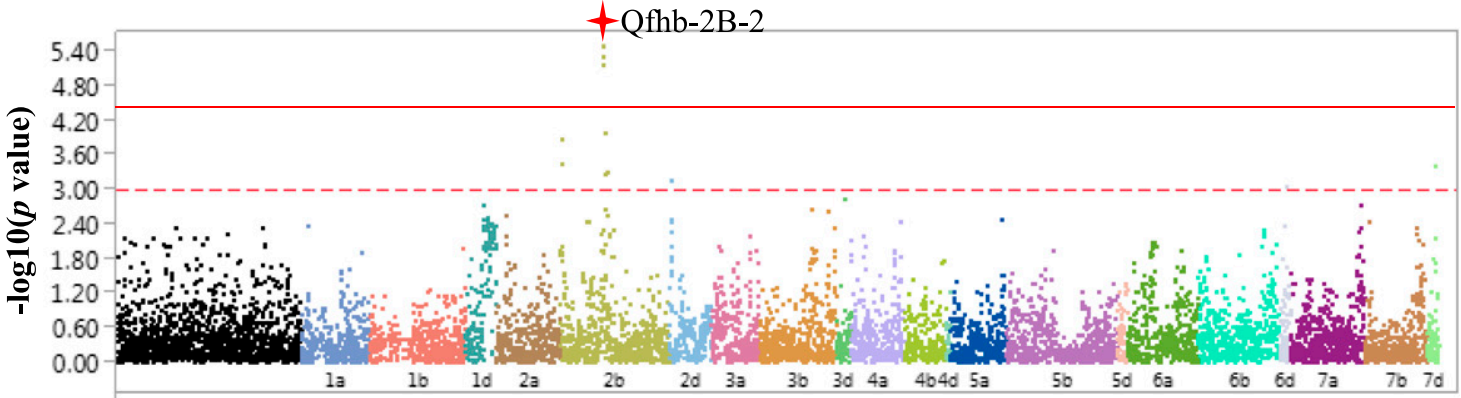

StP15 DON

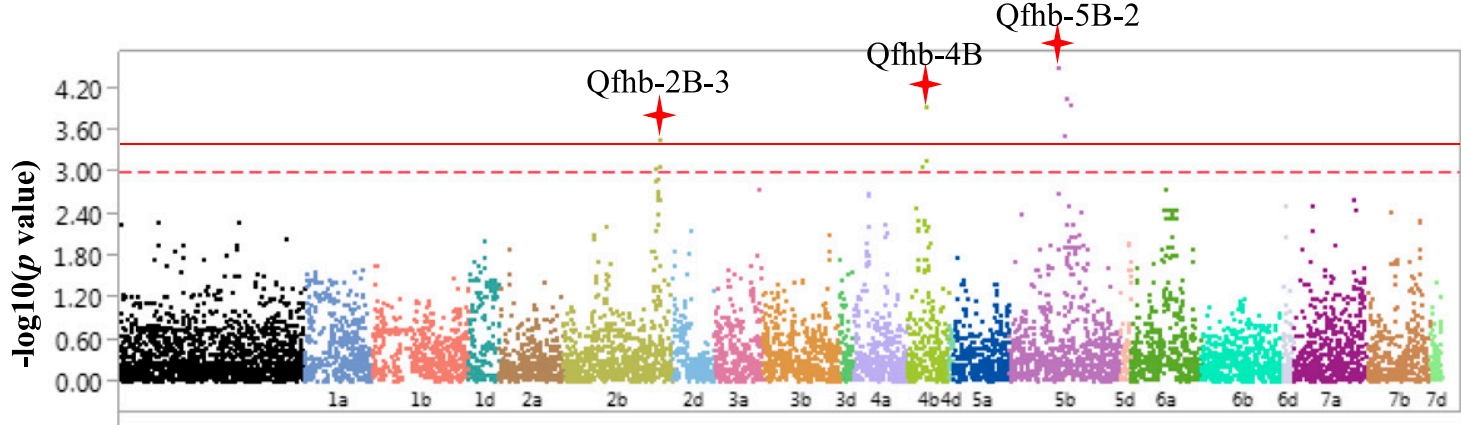

\section{CrK15_DON}

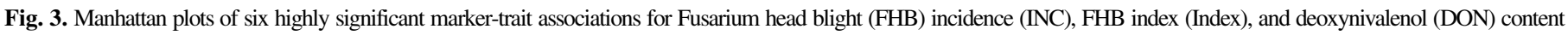

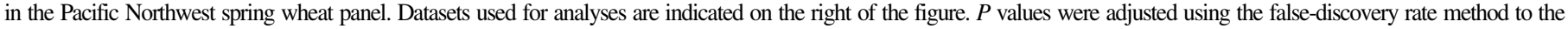
$q$ values. The criterion of highly significant single-nucleotide polymorphism marker is indicated by the solid line at $q$ value $=0.1$. Stars indicate the significant markers. 
linked markers. Meanwhile, the identified QTL are being validated in additional biparental mapping studies.

In the past 20 years, many FHB resistance QTL were identified across all 21 wheat chromosomes using both biparental (Buerstmayr et al. 2009; Liu et al. 2009) and association (Arruda et al. 2016; Kollers et al. 2013; Li et al. 2016; Miedaner et al. 2011) mapping methods. In the present study, nine QTL were identified on chromosomes $1 \mathrm{~B}, 2 \mathrm{~B}, 4 \mathrm{~B}, 5 \mathrm{~A}, 5 \mathrm{~B}$, and $6 \mathrm{~A}$ using four types of phenotypic data and high-density SNP genotypic data. The comparison of these QTL with previous identified ones are summarized as follows:

Chromosome 1B. One QTL was identified on 1BS at 43.7 to $56.7 \mathrm{cM}$. In this region, several FHB resistance QTL were reported previously (Buerstmayr et al. 2009; Liu et al. 2009). In the study of Jiang et al. (2015), a significant SNP marker (Kukri_c40439_366) was detected on 1BS at $57.31 \mathrm{cM}$. This marker might represent the same QTL (Qfhb-1B) identified in the present study. However, this marker was not included in our association analysis and, thus, cannot be compared directly.
Chromosome 2B. This chromosome contains the highest number of resistance QTL in the present study. Qfhb-2B-1 is located near the centromere at 82.4 to $85.2 \mathrm{cM}$. For this region, Jiang et al. (2015) detected a significant SNP marker at $74.67 \mathrm{cM}$. Another two QTL were also detected in the similar region in two FHB association analysis studies (Kollers et al. 2013; Miedaner et al. 2011). The other two QTL (Qfhb-2B-2 and Qfhb-2B-3) located on the long arm of chromosome $2 \mathrm{~B}$ in the present study. For this large region, at least five QTL have been identified previously (Buerstmayr et al. 2009). However, because no consensus map is available between the 90K SNP markers and SSR markers used in previous studies, the novelty of these two QTL is uncertain.

Chromosome 4B. One QTL was identified on the long arm of chromosome 4B at 59.5 to $65.7 \mathrm{cM}$ in the present study. Previous studies reported several resistance QTL on 4B, some of which were located at the similar region for Qfhb-4B (Buerstmayr et al. 2009; Liu et al. 2009). In addition, one QTL with the associated marker BS00084226_51 at the same position $(65.7 \mathrm{cM})$ was identified by Jiang et al. (2015) and could be identical to Qfhb-4B.

TABLE 4. Highly significant quantitative trait loci (QTL) and single-nucleotide polymorphisms (SNP) associated with resistance to different Fusarium head blight traits of spring wheat

\begin{tabular}{|c|c|c|c|c|c|c|c|c|}
\hline Trait $^{\mathrm{a}}$ & QTL & Position $(\mathrm{cM})^{\mathrm{b}}$ & Significance $^{c}$ & SNP & Position & $P$ value & $R^{2}(\%)$ & $q$ Value \\
\hline \multirow[t]{2}{*}{ Incidence } & Qfhb-2B-1 & $82.72-85.22$ & $\begin{array}{l}\text { AB15ns } \\
\text { AB16*** }\end{array}$ & IACX7505 & 83.58 & 4.89E-04 & 7.25 & 0.69 \\
\hline & & & $\begin{array}{l}\text { StP15***d } \\
\text { StP16** } \\
\text { BLUP** }\end{array}$ & BS00009962_51 & 85.22 & $1.55 \mathrm{E}-06$ & 13.25 & 0.02 \\
\hline \multirow[t]{5}{*}{ FHB index } & Qfhb-5B-1 & $14.59-20.23$ & $\mathrm{AB} 15 \mathrm{~ns}$ & BS00022336_51 & 19.66 & $2.79 \mathrm{E}-03$ & 5.35 & 0.94 \\
\hline & & & & BS00079185_51 & 19.66 & $1.85 \mathrm{E}-03$ & 5.79 & 0.94 \\
\hline & & & $\mathrm{AB} 16^{* *}$ & BS00065732_51 & 20.23 & $3.25 \mathrm{E}-05$ & 10.20 & 0.07 \\
\hline & & & BLUP***d & RAC875_c43191_473 & 20.23 & $2.26 \mathrm{E}-05$ & 10.65 & 0.07 \\
\hline & & & & RAC875_rep_c114631_389 & 20.23 & $3.25 \mathrm{E}-05$ & 10.20 & 0.07 \\
\hline \multirow{17}{*}{ DONC } & Ofhb-2B-2 & $96.14-98.04$ & $\mathrm{AB} 15^{* * *}$ & BS00043103 51 & 96.14 & $3.28 \mathrm{E}-06$ & 12.54 & 0.02 \\
\hline & & & (18 & Excalibur_c44495_105 & 96.14 & $4.93 \mathrm{E}-06$ & 12.05 & 0.02 \\
\hline & & & CrK15* & TA001322_1176 & 96.14 & 7.06E-06 & 11.74 & 0.02 \\
\hline & & & & IAAV5331 & 96.14 & 4.99E-03 & 4.74 & 0.69 \\
\hline & Qfhb-2B-3 & $130.29-134.46$ & $\mathrm{AB} 15^{* *}$ & RFL_Contig3761_791 & 134.46 & $2.52 \mathrm{E}-03$ & 5.70 & 0.25 \\
\hline & & & & RAC875_c5949_2011 & 134.46 & $8.41 \mathrm{E}-04$ & 6.92 & 0.10 \\
\hline & & & $\mathrm{CrK} 15^{* * * * \mathrm{~d}}$ & Kukri_c74469_351 & 134.46 & $3.67 \mathrm{E}-04$ & 7.84 & 0.05 \\
\hline & & & & Kukri_c21087_79 & 134.46 & $1.30 \mathrm{E}-03$ & 6.52 & 0.15 \\
\hline & & & StP15ns & IACX8947 & 134.46 & $4.15 \mathrm{E}-03$ & 5.11 & 0.35 \\
\hline & & & & GENE_0526_733 & 134.46 & $1.94 \mathrm{E}-03$ & 5.95 & 0.21 \\
\hline & & & StP16ns & Excalibur_c9752_73 & 134.46 & $2.30 \mathrm{E}-03$ & 5.80 & 0.23 \\
\hline & & & & Excalibur_c9752_670 & 134.46 & $2.52 \mathrm{E}-03$ & 5.70 & 0.25 \\
\hline & & & BLUP** & BobWhite_rep_c50285_700 & 134.46 & $9.30 \mathrm{E}-04$ & 6.81 & 0.11 \\
\hline & & & & BobWhite_c10864_436 & 134.46 & $1.37 \mathrm{E}-03$ & 6.33 & 0.15 \\
\hline & Qfhb-4B & $59.94-65.70$ & $\mathrm{AB} 15 \mathrm{~ns}$ & Ex_c28329_716 & 59.94 & 4.91E-03 & 4.90 & 0.38 \\
\hline & & & & BobWhite_c38340_243 & 59.94 & $3.39 \mathrm{E}-03$ & 5.30 & 0.31 \\
\hline & & & $\mathrm{CrK} 15 * * * \mathrm{~d}$ & Excalibur_c29141_864 & 62.56 & $8.76 \mathrm{E}-04$ & 6.79 & 0.10 \\
\hline
\end{tabular}

a Fusarium head blight (FHB) incidence, deoxynivalenol content (DONC), and FHB index. BLUP = best linear unbiased predictions.

${ }^{b}$ Position in centimorgans $(\mathrm{cM})$.

c Significance: *** indicates $q$ (positive false discovery rate) $<0.1$, ** indicates $P<0.001$, * indicates $P<0.01$, and ns indicates not significant. Locations:

St. Paul, MN (StP), Crookston, MN (CrK), and Aberdeen, ID (AB) in 2015 and 2016.

d Only the markers in this dataset are reported here. 
Chromosome 5A. One QTL was identified on the long arm of chromosome 5A at 129.9 to $137.9 \mathrm{cM}$ in the present study. Jiang et al. (2015) identified 13 significantly associated markers in the same region, ranging from 91.99 to $141.74 \mathrm{cM}$. Also, He et al. (2016) detected a resistance QTL on the similar region of chromosome 5AL. All of these loci maybe the same as Qfhb.rwg-5A.2 detected by Chu et al. (2011), located on the 5AL region close to the telomere.

Chromosome 5B. Two QTL (Qfhb-5B-1 and Qfhb-5B-2) were identified on the short arm of chromosome $5 \mathrm{~B}$ in the present study. Although the previous four FHB association studies did not detect any QTL on 5BS (Arruda et al. 2016; Kollers et al. 2013; Li et al. 2016; Miedaner et al. 2011), one QTL located in the 5BS region close to the telomere was identified in wheat line Wangshuibai (Liu et al. 2009). Qfhb-5B-1 may represent the same locus as that identified from Wangshuibai. For Qfhb-5B-2, no known QTL was identified in this similar region; it may represent a novel QTL conferring resistance to DON content (Arruda et al. 2016; Buerstmayr et al. 2009; Kollers et al. 2013; Li et al. 2016; Liu et al. 2009; Miedaner et al. 2011).
Chromosome 6A. One QTL was identified on the long arm of chromosome $6 \mathrm{~A}$ at 82.4 to $85.1 \mathrm{cM}$ in the present study. In the same region, Jiang et al. (2015) identified seven significantly associated markers, located from 62.77 to $82.38 \mathrm{cM}$ based on the same consensus genetic map.

The major FHB resistance QTL Fhbl located on 3BS was first identified in Sumai 3 and confirmed in Wangshuibai and, since then, has been introgressed into U.S. elite wheat lines. Arruda et al. (2016) showed that 3BS QTL was associated with severity, FHB index, and DON content in a winter wheat panel consisting of 273 winter wheat breeding lines from the midwestern and eastern regions of the United States. In addition, the Fhbl-associated markers were also identified in an association mapping study using 195 Chinese and Japanese wheat commercial varieties and landraces (Li et al. 2016). However, based on pedigree information derived from the $\mathrm{T} 3$ and more detailed investigation in the GRIN-Global database (https://training.ars-grin. gov/gringlobal/search.aspx), most of the lines in the PNW panel have neither Sumai 3 nor Sumai 3-related lines in their background. Thus, although the LD analysis indicated that 14 markers located at 14.11

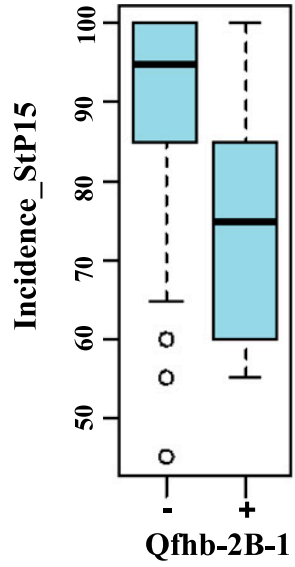

Mean with $95 \%$ confidence interval

$$
\begin{gathered}
P \text { value from } t \text { test } \\
\text { QTL effect }(\%)
\end{gathered}
$$$$
90.55 \pm 1.8875 .00 \pm 6.34
$$$$
<0.0001
$$$$
17.17
$$

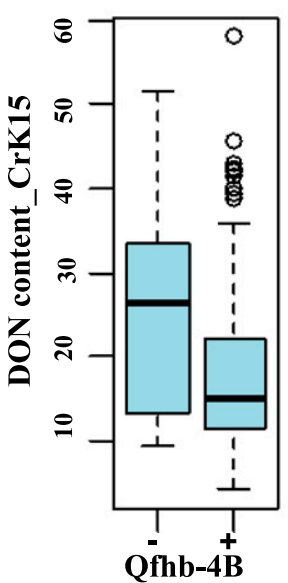

Mean with $95 \%$ confidence interval

$$
P \text { value from } t \text { test }
$$$$
\text { QTL effect (\%) }
$$

$26.58 \pm 6.01 \quad 17.89 \pm 1.56$

0.0002

32.69

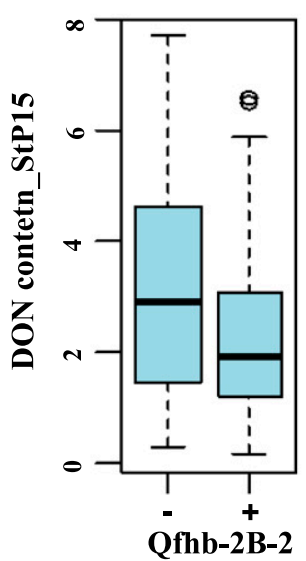

$$
3.18 \pm 0.502 .24 \pm 0.28
$$

0.0006

31.25

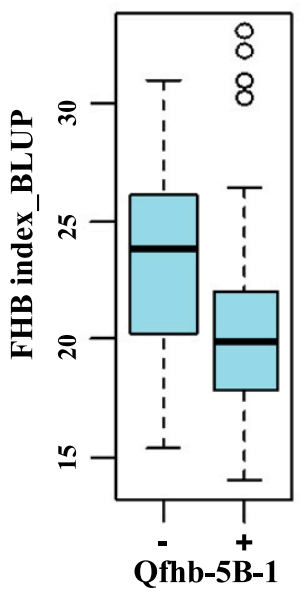

$23.51 \pm 0.9220 .28 \pm 0.63$

$<0.0001$

13.74

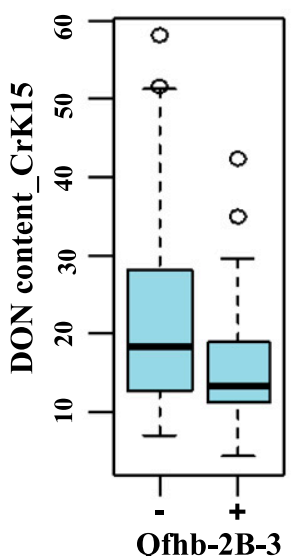

$21.72 \pm 2.5215 .88 \pm 1.64$

0.0003

26.89

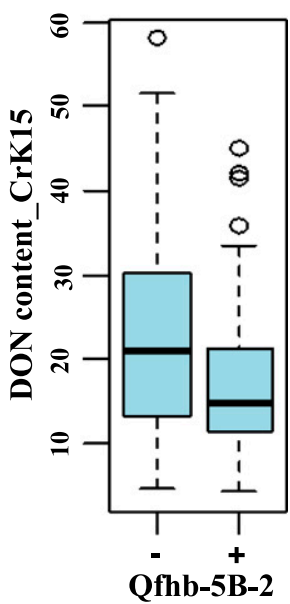

$24.10 \pm 3.70 \quad 16.83 \pm 1.49$

$<0.0001$

30.17

Fig. 4. Effect of the six highly significant quantitative trait loci (QTL) on different Fusarium head blight (FHB) traits in the Pacific Northwest spring wheat panel shown by distributions of FHB incidence, FHB index, and deoxynivalenol (DON) content for wheat lines carrying the unfavorable alleles (symbol -) and the lines with the favorable alleles (symbol + ) of each QTL. The QTL effect $=$ (the mean of infection responses of lines carrying the unfavorable alleles of QTL - the mean of infection responses of lines carrying the favorable alleles of QTL)/the mean of infection responses of lines carrying the unfavorable alleles of QTL $\times 100 \% . P$ values and the means with $95 \%$ confidence intervals from $t$ tests are listed under the boxplots, indicating the statistical difference between two groups of wheat lines. 
A

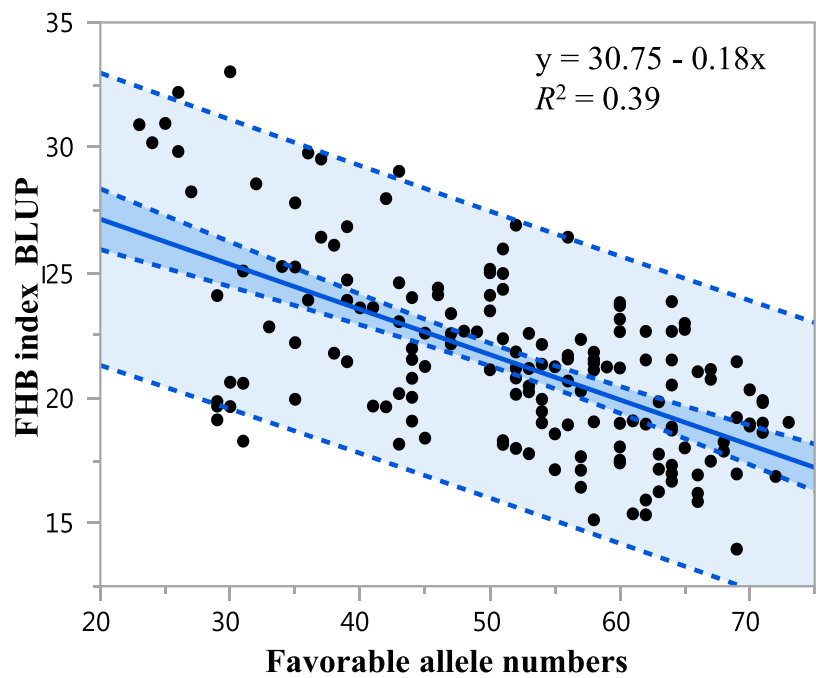

B

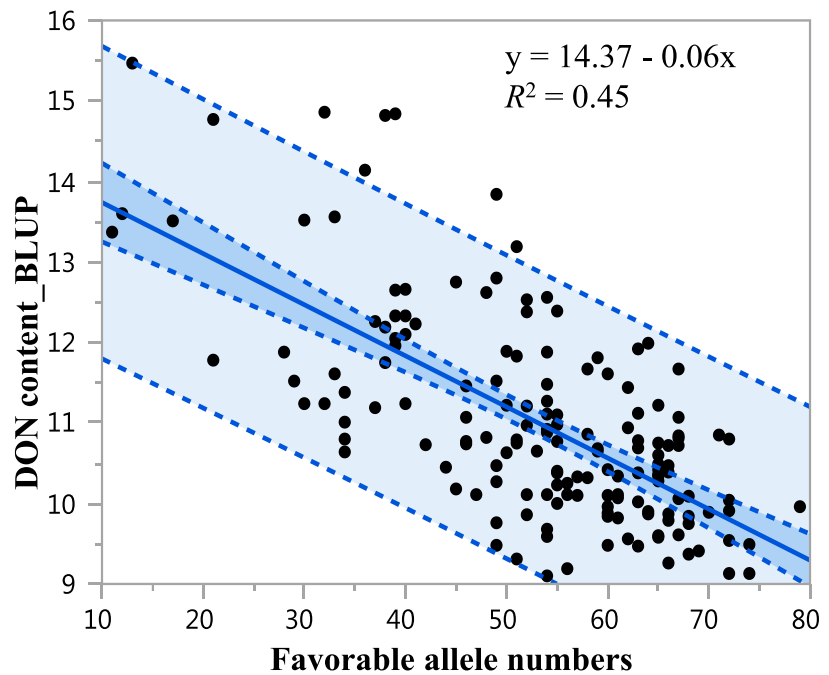

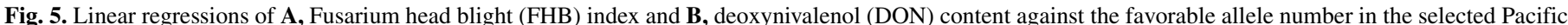

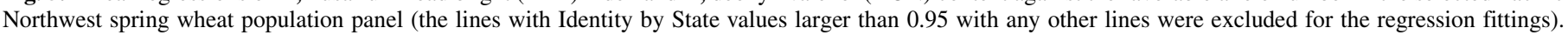
Both regressions were highly significant $(P<0.0001)$.

to $32.99 \mathrm{cM}$ on chromosome $3 \mathrm{~B}$ were in high $\mathrm{LD}$ ( $r^{2}$ values of 0.61 to 0.81 ) with the umnl0 STS marker for Fhbl, none of these 15 markers (14 SNP and umn10) were significantly associated with FHB resistance in our analysis. In addition, the presence of $u n m 10$ was noncorrelated with eight sets of severity phenotyping data ( $r^{2}$ of -0.18 to 0.09 ). These results support the hypothesis that the Fhbl locus is rare or absent in the PNW panel and provide valuable information for our breeding work for pyramiding multiple FHB resistances.

It is well known that FHB resistance is controlled by a relatively large number of quantitative loci, some with only minor effects. In recent years, genomic selection (GS) is increasingly popular in wheat breeding for quantitative traits, because it considers all loci in the analysis and in breeding practice. In the present study, we fitted linear regressions between phenotype data and the total favorable allele numbers for all detected markers with $P$ value $<0.01$. The relatively large variation (39\% for FHB index and $45 \%$ for DON content) explained by different numbers of favorable alleles (Fig. 5) for all detected resistance QTL suggests that the GWAS results could be useful for analyzing the effect of genetic architecture on GS prediction accuracy for resistance to FHB, which is required for effective utilization of GS (Spindel et al. 2015; Wimmer et al. 2013).

In summary, we characterized the FHB resistance in 170 spring wheat lines developed in the PNW and CIMMYT by GWAS. We identified a few resistant lines that have no Sumai 3 or Sumai 3related background but show a level of FHB resistance similar to that of Sumai 3. These lines are valuable resources in wheat variety improvement of FHB resistance. We also found six highly significant QTL and three QTL with smaller effects on six chromosomes. One QTL located on 5BS may represent a novel QTL conferring resistance to DON accumulation. In addition, significant additive effects for resistance were found in this panel, indicating that genomic selection can be applied to these materials for breeding FHB-resistant cultivars.

\section{ACKNOWLEDGMENTS}

We thank spring wheat breeders J. Dubcovsky, L. Talbert, and M. Pumphrey for their contributions to wheat lines used in this study; S. Reynolds for assistance in the phenotyping process; and J. M. Bonman and L. Talbert for reviewing the manuscript. This research was supported by the USDA-ARS U.S. Wheat and Barley Scab Initiative and the National Research Initiative Competitive Grants 2011-68002-30029 and 201767007-25939 from the USDA National Institute of Food and Agriculture.

\section{LITERATURE CITED}

Arruda, M. P., Brown, P., Brown-Guedira, G., Krill, A. M., Thurber, C., Merrill, K. R., Foresman, B. J., and Kolb, F. L. 2016. Genome-wide association mapping of Fusarium head blight resistance in wheat using genotyping-bysequencing. Plant Genome 9. doi:10.3835/plantgenome2015.04.0028

Bai, G. H., Plattner, R., Desjardins, A., and Kolb, F. 2001. Resistance to Fusarium head blight and deoxynivalenol accumulation in wheat. Plant Breed. 120:1-6.

Bai, G. H., and Shaner, G. 1996. Variation in Fusarium graminearum and cultivar resistance to wheat scab. Plant Dis. 80:975-979.

Bajgain, P., Rouse, M. N., Bulli, P., Bhavani, S., Gordon, T., Wanyera, R., Njau, P. N., Legesse, W., Anderson, J. A., and Pumphrey, M. O. 2015. Association mapping of North American spring wheat breeding germplasm reveals loci conferring resistance to Ug99 and other African stem rust races. BMC Plant Biol. 15:249.

Bates, D., Mächler, M., Bolker, B. M., and Walker, S. C. 2015. Fitting linear mixed-effects models using lme4. J. Stat. Softw. 67:1-48.

Buerstmayr, H., Ban, T., and Anderson, J. A. 2009. QTL mapping and markerassisted selection for Fusarium head blight resistance in wheat: A review. Plant Breed. 128:1-26.

Chao, S. M., Dubcovsky, J., Dvorak, J., Luo, M. C., Baenziger, S. P., Matnyazov, R., Clark, D. R., Talbert, L. E., Anderson, J. A., Dreisigacker, S., Glover, K., Chen, J., Campbell, K. Bruckner, P. L., Rudd, J. C., Haley, S., Carver, B. F., Perry. S., Sorrells, M. E., and Akhunov, E. D. 2010. Population- and genome-specific patterns of linkage disequilibrium and SNP variation in spring and winter wheat (Triticum aestivum L.). BMC Genomics 11:727.

Chen, J., Fanelli, J., Griffey, C., Paling, J., Maroof, M., and Brown-Guedira, G. 2007. Progress in Development and MAS of FHB Resistant Wheat Cultivars and Germplasm at Virginia Tech. In: Natl. Fusarium Head Blight Forum Proc.

Chen, J., Griffey, C. A., Saghai Maroof, M. A., Stromberg, E. L., Biyashev, R. M., Zhao, W., Chappell, M. R., Pridgen, T. H., Dong, Y., and Zeng, Z. 2006. Validation of two major quantitative trait loci for Fusarium head blight resistance in Chinese wheat line W14. Plant Breed. 125:99-101.

Chen, J., and Marshall, J. 2012. Evaluation of FHB resistance in PNW spring wheat lines. Idaho Grain 1:18-19.

Chu, C., Niu, Z., Zhong, S., Chao, S., Friesen, T. L., Halley, S., Elias, E. M., Dong, Y., Faris, J. D., and Xu, S. S. 2011. Identification and molecular mapping of two QTLs with major effects for resistance to Fusarium head blight in wheat. Theor. Appl. Genet. 123:1107-1119.

Desjardins, A. E., Hohn, T. M., and McCormick, S. P. 1993. Trichothecene biosynthesis in fusarium species-Chemistry, genetics, and significance. Microbiol. Rev. 57:595-604.

Fuentes, R. G., Mickelson, H. R., Busch, R. H., Dill-Macky, R., Evans, C. K., Thompson, W. G., Wiersma, J. V., Xie, W., Dong, Y., and Anderson, J. A. 2005. Resource allocation and cultivar stability in breeding for Fusarium head blight resistance in spring wheat. Crop Sci. 45:1965-1972.

He, X., Lillemo, M., Shi, J., Wu, J., Bjornstad, A., Belova, T., Dreisigacker, S., Duveiller, E., and Singh, P. 2016. QTL characterization of Fusarium head 
blight resistance in CIMMYT bread wheat line Soru\#1. PLoS One 11: e0158052.

Jiang, Y., Zhao, Y., Rodemann, B., Plieske, J., Kollers, S., Korzun, V., Ebmeyer, E., Argillier, O., Hinze, M., Ling, J., Röder, M. S., Ganal, M. W., Mette, M. F., and Reif, J. C. 2015. Potential and limits to unravel the genetic architecture and predict the variation of Fusarium head blight resistance in European winter wheat (Triticum aestivum L.). Heredity 114:318-326.

Kollers, S., Rodemann, B., Ling, J., Korzun, V., Ebmeyer, E., Argillier, O., Hinze, M., Plieske, J., Kulosa, D., Ganal, M. W., and Röder, M. S. 2013. Whole genome association mapping of Fusarium head blight resistance in European winter wheat (Triticum aestivum L.). PLoS One 8:e57500.

Li, T., Zhang, D. D., Zhou, X. L., Bai, G. H., Li, L., and Gu, S. L. 2016. Fusarium head blight resistance loci in a stratified population of wheat landraces and varieties. Euphytica 207:551-561.

Liu, S. Y., Hall, M. D., Griffey, C. A., and McKendry, A. L. 2009. Metaanalysis of QTL associated with Fusarium head blight resistance in wheat. Crop Sci. 49:1955-1968.

Marshall, J. 2014. Fusarium Head Blight Forum IBC/UI. Online publication. https://barley.idaho.gov/pdf/FHB/2014\%20-\%20FHB\%20Forum\%20 Marshall.pdf

Marshall, J., Bissonnette, K., and Chen, J. 2012. IMPACT, University of Idaho Extension. Online publication. http://www.extension.uidaho.edu/impacts/ Pdf_12/30-12jmarshall-fusarium.pdf

Mergoum, M., Frohberg, R. C., and Stack, R. W. 2007. Breeding hard red spring wheat for Fusarium head blight resistance, successes and challenges. Pages 161-167 in: Wheat Production in Stressed Environments, Vol. 12. H. T. Buck, J. E. Nisi, and N. Salomón, eds. Springer, Dordrecht, The Netherlands.

Mesterhazy, A. 1995. Types and components of resistance to Fusarium head blight of wheat. Plant Breed. 114:377-386.

Mesterhazy, A., Bartok, T., Mirocha, C. G., and Komoroczy, R. 1999. Nature of wheat resistance to Fusarium head blight and the role of deoxynivalenol for breeding. Plant Breed. 118:97-110.

Miedaner, T., Wurschum, T., Maurer, H. P., Korzun, V., Ebmeyer, E., and Reif, J. C. 2011. Association mapping for Fusarium head blight resistance in European soft winter wheat. Mol. Breed. 28:647-655.

Mirocha, C. J., Kolaczkowski, E., Xie, W., Yu, H., and Helen, H. 1998. Analysis of deoxynivalenol and its derivatives (batch and single kernel) using gas chromatography/mass spectrometry. J. Agric. Food Chem. 46: 1414-1418.

Narayanan, S., and Prasad, P. V. V. 2014. Characterization of a spring wheat association mapping panel for root traits. Agron. J. 106:1593-1604.

R Core Team. 2016. R: A Language and Environment for Statistical Computing. R Foundation for Statistical Computing, Vienna. https://www.Rproject.org/

Schroeder, H. W., and Christensen, J. J. 1963. Factors affecting resistance of wheat to scab caused by Gibberella Zeae. Phytopathology 53:831-838.

Spindel, J., Begum, H., Akdemir, D., Virk, P., Collard, B., Redoña, E., Atlin, G., Jannink, J.-L., and McCouch, S. R. 2015. Genomic selection and association mapping in rice (Oryza sativa): Effect of trait genetic architecture, training population composition, marker number and statistical model on accuracy of rice genomic selection in elite, tropical rice breeding lines. PLoS Genet. 11:e1004982.

Storey, J. D. 2002. A direct approach to false discovery rates. J. R. Stat. Soc. Ser. B Stat. Methodol. 64:479-498.

Tamang, P., Neupane, A., Mamidi, S., Friesen, T., and Brueggeman, R. 2015. Association mapping of seedling resistance to spot form net blotch in a worldwide collection of barley. Phytopathology 105:500-508.

Wang, R., Leng, Y., Ali, S., Wang, M., and Zhong, S. 2017. Genome-wide association mapping of spot blotch resistance to three different pathotypes of Cochliobolus sativus in the USDA barley core collection. Mol. Breed. $37: 44$.

Wang, S., Wong, D., Forrest, K., Allen, A., Chao, S., Huang, B. E. 2014. Characterization of polyploid wheat genomic diversity using a high-density 90000 single nucleotide polymorphism array. Plant Biotechnol. J. 12: 787-796.

Wimmer, V., Lehermeier, C., Albrecht, T., Auinger, H. J., Wang, Y., and Schon, C. C. 2013. Genome-wide prediction of traits with different genetic architecture through efficient variable selection. Genetics 195:573-587.

Windels, C. E. 2000. Economic and social impacts of Fusarium head blight: Changing farms and rural communities in the Northern Great Plains. Phytopathology 90:17-21.

Zhang, X., Rouse, M. N., Nava, I. C., Jin, Y., and Anderson, J. A. 2016. Development and verification of wheat germplasm containing both $\mathrm{Sr} 2$ and Fhb1. Mol. Breed. 36:85. 